Roger G. van de Velde

\title{
On Deceptive Data of Language Interpretation
}

\section{Introduction}

This paper is a partial response to the conception of linguistic theory construction as is present in Jensen, Sørensen, Vikner (Hermes, 1989, 2, 179-186). In their view, a theory should meet explanatory, predictive and unifying requirements. The present paper will examine whether this normative view can be satisfied. It will be concerned with the question of what linguistic theories can do. More specifically, it will tackle the following problem: is there a linguistic theory which can explain and predict and unify the interpretation data of language use ? This problem has been selected for two reasons: first, any kind of language use requires the solution to interpretation problems; second, any kind of linguistic research has also to solve problems of interpretation (Van de Velde 1984; 1986b; 1988c).

In the following, I will not be concerned with all aspects of interpretation. I will take into account only some deceptive aspects of interpretative activities and of their exegetic results. From tackling the problem of self-deception I will make it clear and plausible that a general, all-inclusive and unifying theory of language interpretation does not yet exist and that, as a consequence, much theorizing about linguistic theories is of a premature and potentially deceptive nature.

Let me begin with a critical remark: many methodological views on linguistic theory construction neglect the obvious fact that language cannot be isolated from man (see also Moore/Carling 1982). This neglect shows a grievous lack of realism, because any use of language which has a communicative function requires both a producer of language and a receiver of language. Reciprocal interpretation is then a major ingredient of their communicative activities.

A major part of this paper will focus on the producer and on the identification of those person-internal interpretation data which are anterior to her/his verbal behaviour. This focus is grounded in the background assumptions that every meaning (conveyance) requires a meaner and that every meaning assignment is incomplete, implausible and inappropriate if the meaner's meaning is overlooked. It is also based on the view that 
realized language has no communicative reason to exist if it has no destination. Its destination is in the receiver (Van de Velde 1988c). As will be seen in this paper, it is the immense variability of meaning effects which realized language may produce in the receiver that raises difficulties for theory construction.

Let me now give some clarifications to the notion of 'interpretation'. This notion may refer, in first order, to the activities which are concerned with the assignment of meaning. In second order, the word 'interpretation' may denote the results of the exegetic activities of the receiver's conscious mind.

When the phrase 'assignment of meaning' occurs, the word 'meaning' itself needs clarification. Let me put things briefly: 'meaning' may have to do with the properties of language. 'Meaning' may also concern properties outside language: these properties may be in the producer, in the receiver or in the interpersonal relationships. 'Meaning' also belongs to the properties of the language-external reality to which language refers. The following sections will be concerned with these properties of meaning. Section 2 wil be devoted to meaning as a property of language; section 3 will deal with meaning which is in the producder; section 4 will consider the properties of meaning as they are recognized in the interpersonal relationships between the producer and the receiver; section 5 will account for the properties of meaning which have to do with the person-external reality. For all these properties of meaning it will be shown that their identification has to face the fascination of mystery and may give rise to illusion and self-deception.

Any time the phrase 'assignment of meaning' is used, one may believe that there is something like meaning. Many philosophers (of language), however, are opposed to this belief. They claim that there is no such thing as meaning or that, even if meaning is erroneously supposed to exist, it still cannot be grasped in a justifiable way. Needless to remind the reader here of the fact that many 20th century descriptivist linguists have held similar convictions or displayed outright semeophobic signals (Moore/Carling 1982).

In the light of these philosophical (and descriptivist) claims, it is worthwhile inquiring whether attempts at constructing theories of language interpretation and the related research on meaning are working on illusions. In this respect, it may also be asked whether the practice of interpretation is concerned with illusions. The present paper will succinctly concentrate on these questions. 
As to the words 'illusion' and 'self-deception', I am aware that their use is emotionally loaded in a negative sense. But I still prefer 'illusion' and 'self-deception' to words such as 'false belief', 'erroneous conjecture', and the like. This paper will not offer a definition of 'illusion' and 'self-deception'. Nor will it specify the necessary and sufficient conditions of what it is to have an illusion or to experience self-deception. It would be really utopian if not quixotic to attempt to do so. Such an attempt would have to cope with the enormous difficulty that the information/meaning parts of human (verbal) activities are immensely variable and largely beyond control. The present paper can only approximate to what it is to be under an illusion and to experience entrapment or self-deception when meaning is assigned to language. More specifically, it will suggest a sceptical philosophical attitude by arguing that there is no rigorous testing of the conjectures about verbalized meanings.

\section{On the existence of illusions about language meaning}

Suppose that someone writes a letter to a friend in which (s)he puts down the message (1). The problems of interpretation raised by (1) can be reduced to the bare minimum of coping with its graphemic, morphological and syntactic characteristics. Or they can be restricted to the identification of the structural relations between the words of (1) and, in particular, be confined to the low-level stages of parsing (Garnham 1988, $146 \mathrm{ff})$.

(1) I may love her.

It may, however, also be the case that the receiver goes further than the preliminary steps towards understanding (1). She/he may be interested in retracing the huge variety and the complications of the human emotion which are denoted by the main lexical element love. Or the receiver may be puzzled by the problems of modality which arise from the verb may. Or it may happen that (s)he is deeply concerned with the reference problems which are raised by the pronoun her. In connection with these reference problems, the receiver may attempt to solve the problem of whether (1) imparts information about the attachment to the mother or to someone else, etc. Such concerns with the meaning and reference problems of (1) may start from the following paraphrases about the propositional content of (1) (see also Levinson 1983, $140 \mathrm{ff}$ ):

(1a) It is possible that I love her

(1b) It is possible that I do not love her.

The message (1) may also have conveyed a meaning which is not in 
the paraphrases (1a) and (1b). This is suggested by the vertical dots under (1b). For instance, (1) may have signalized that the producer has the permission to love her, that it is unsure whether (s)he loves her or whether (s)he does not love her, and so on. Additional readings of (1) urge themselves upon the receiver when (s)he wants to uncover whether (1) implicitly refers to the end of the producer's worries, negative mood state, depressive thoughts, emotional disorders, and the like. Did the producer of (1) impart her/his previous (over-)awareness of emotionally threatening or quietening information? Or did (s)he show a selective attention to her/ his need for affection and intimacy? Or did the producer convey that her/ his feelings of loneliness, helplessness or psychological incompatibility with the her-person have come to an end? Or did (1) symbolize resistence against resignation, indifference or apathy? Or did (1) impart contentment, relief or happiness? Did the producer of (1) display her/his prudence or caution? Or did (s)he convey her/his unwillingness to commit herself/himself to a clear position?

Let me make here the following point: any interpretative endeavour which aims at coping with (1) is a matter of the receiver's and the producer's ego-consciousness. I use the term 'ego-consciousness' to differentiate the 'inner universe' of the individual from the collective 'inner universe' of people who are socially/culturally organized as groups, tribes, nations, etc. Ego-consciousness is complementary to collective consciousness and vice versa.

When the content of ego-consciousness is affected in its characteristics, it is because ego-consciousness relates to the outside world (including the psychological world of collective consciousness). The present paper cannot go into the enormous diversity of these (mutual) relationships.

As to language interpretation, the receiver can free himself/herself from a temporary illusion. To this end, (s)he can switch to a different reading, and if this does not work, continue his/her problem solving activities until a justified, plausible and/or appropriate interpretation has been found.

Here, a terminological clarification about what is a justified, plausible and/or appropriate interpretation is in order: an interpretation is justified when the activities involved obey the rules of logic, when the required language-directed inferences are made (Van de Velde 1986b) and when the interpretative results can be rationally controlled. An interpretation is plausible to the extent that there is more evidence in favour of it than can 
be adduced to sustain any other interpretation. An interpretation is appropriate depending on its maximal degree of fitting in the communicative context. Plausible interpretations and/or appropriate interpretations allow of more freedom than justified interpretations.

Most linguistic studies of meaning do not consider the crux that a person who assigns meaning to a fragment of language may have been trapped into illusion. As long as one is only concerned with the propositional content of verbal messages (as is exemplified in (1a) and in (1b)), one may feel free from being trapped into illusion. However, the risks of illusion increase when the disentanglement of meaning intricacies goes further and deeper than the propositional content of language. This is partly due to the fact that meaning is not completely and not explicitly expressed in a verbal message (Van de Velde 1988c) and that it is rarely possible to make the producer's meanings converge with the diverse hypotheses which the receiver constructs about them (Moore/Carling 1988). Let me make these points clear by considering a communicative situation in which the message (2) is sent to an interested (fe)male addressee.

(2) I may not love her.

The most obvious interpretations of the propositional content of (2) are given in (2a) and (2b). However, it is possible to elaborate on the formal representations of ( $2 a)$ and ( $2 b)$ by developing the equivalence relations of $\mathrm{M} \neg \mathrm{p}$ and $\mathrm{M} \neg \mathrm{p}$ into (2c) and (2d). Subsequently one can reinterpret (2c) into (2e) and transform (2d) into (2f).

\footnotetext{
(2a) It is possible that I will not love her

(which can be formally represented as ' $\mathrm{M} \neg \mathrm{p}$ ')

(2b) It is not possible that I will love her

(which can be formally represented as ' $\neg \mathrm{Mp}$ ')

(2c) It is not necessary that I will love her

(because of $\mathrm{M} \neg \mathrm{p} \longleftrightarrow \mathrm{N} \neg \neg \mathrm{p}$ and $\neg \mathrm{N} \neg \neg \mathrm{p} \longleftrightarrow \longrightarrow \neg \mathrm{Np}$ )

(2d) It is necessary that I will not love her

(because of $\neg \mathrm{Mp} \longleftrightarrow \longrightarrow \neg \neg \mathrm{N} \neg \mathrm{p}$ and $\neg \neg \mathrm{N} \neg \mathrm{p} \longleftrightarrow \longrightarrow \mathrm{N} \neg \mathrm{p}$ )

(2e) I allow myself to not love her

(2f) I forbid myself to love her
}

The logically inspired comment on (2) should not distract from the fact that still more meanings can be assigned to (2), as is suggested by the readings ( $2 \mathrm{~g})-(2 \mathrm{j})$ and by the vertically arranged dots under (2f) and under (2j). In addition, (2) may also be interpreted as 'it is possible that I 
do not love her' or as 'I may be mistaken in thinking that I love her', etc. In the light of the multiple readings of (2), one may assume that the interpretation of the written medium of language is a more labyrinthine enterprise than the interpretation of many other non-verbal visual data.

( $2 \mathrm{~g}) \mathrm{I}$ have no permission to love her

(2h)Someone else (but not I) has the permission to love her

(2i) I have no permission to love her (but I have the permission to love someone else)

(2j) I have no permission to love her (but to do something else such as to visit her, to help her, to criticize her, etc.)

What is the consequence of the preceding considerations? It is apparent that it would be an illusion to believe that one can precisely know whether the interpretations of (1) and (2) are appropriate, plausible and justified. Concomitantly, it can be seen that there are risks of entrapment and self-deception in coping with language meaning.

\section{Can meaning be precisely and completely uncovered in the producer?}

As becomes clear from the foregoing section and from other sorts of verbal communication, it is undeniable that meaning requires a meaner, i.e. a person who uses a medium to convey what is (going on) in her/his person-internal reality. Here, the following point should be made: the risk of illusion is much higher when one is not only concerned with the meanings which are characteristic of language, but is also interested in the meanings which have originated in the producer and are subsequently conveyed through language by the producer.

As to (1) and (2), the pronoun $I$ is a grammatical and lexical tool for the producer to indicate that what is said refers, in first order, to herself/ himself. Moreover, the modal may is grammatically connected with $I$. From this grammatical connection it can be inferred that the expressed modality is concerned with the producer's attitudes, beliefs, affective states, etc.

These observations make it plausible to claim that there is 'more' to the meaning of (1) and (2) than the identification of its propositional content. I shall refer to this 'more' with the term 'person-internal meaning'. With respect to person-internal meaning, the following caveat is in order: it would be wrong to claim that person-internal meanings are exclusively 
made explicit by using the personal pronoun I in combination with verbs which denote the producer's psychological states. Person-internal meanings can also be conveyed in other ways, as section 5 and the examples (5) and (6) will suggest.

Here, one may already object that all meanings, which are part of a person's ego-consciousness, are person-internal meanings. This objection would only partly hold true, because there are public meanings which we share with others. They may belong to the collective consciousness of the members of the same linguistic community. As such, they are conventionalized standard meanings which are carried along with the words of the specific human natural language which these members use.

Apart from these public meanings, there are also meanings which are not common to ourselves and to others. They are the really person-internal meanings. They are related to the inner life constellations of cognition, affect and conation. I refer to them as meanings of cognitive life, affective life and conative life. All of them are constitutive non-material facets of ego-consciousness.

Coping with the person-internal meanings of the meaner is of utmost significance to all interpretative endeavours about language and about humans who use language. The reason is straightforward: there is a sort of (control) hierarchy between retracing the person-internal meaning and identifying the language-internal meaning. Uncovering the person-internal meaning normally ranks higher than the identification of languageinternal meaning. It even controls and affects the information processing activities which concern the meanings which are characteristic of the language medium. In so doing, the superordinate goal and the of understanding the producer will determine the subordinate goals of comprehending her/his language material. This is particularly the case when ungrammaticalities, malapropisms, speech errors, solecisms and other oddities occur. Then, the superordinate goal of uncovering the personinternal meaning may give rise to controlling and harmonizing mechanisms. Within this particular perspective of interpretation, it is necessary to bring the meaner's ego-consciousness into focus.

\subsection{On ego-consciousness}

About man's ego-consciousness very little is known. To date, most investigators have pinned their faith on scrutinizing its cognitive facets. On the one hand, models of man's inner microcosmos, particularly the models which highlight the man-machine analogies are predominantly, if 
not exclusively, concerned with man's inner cognitive functioning (Johnson-Laird 1983, Garnham 1988 and references therein). On the other hand, there is an exclusive reliance on paradigms of cognitive psychology in order to account for (the disorders of) man's affective life (Williams, e.a. 1988 and references therein). But there is 'more' to human consciousness than its cognitive functioning. However, this 'more' is the darkest and most impenetrable domain.

About this domain one can only speak by means of images and largely uncontrollable comparisons. The images and comparisons which will be used below serve the function of making approximately clear the points which will be made. In this respect, I do not want to produce the illusion that paraphrases $(2 \mathrm{k})-(2 \mathrm{w})$ which will be proposed for inner life facets of (2) can account for the mysteries of person-internal meanings. These paraphrases, however, can show that there is much meaning to be uncovered outside language and that uncovering this language-external meaning is of major importance to understanding the meaner.

Cognitive, affective and conative life are basic facets of a person's ego-consciousness. These basic facets do not function in isolation. It is only for expository purposes that I will treat them separately. In fig. 1, they are enclosed in the sectors of a circle. (This circle results from the horizontal sections which can be made through fig. 2 and fig. 3 . The use of this image will become clear below.) This circle represents the individual's ego-consciousness at a particular moment of self-awareness. In the course of this paper, the term 'ego-consciousness' is sometimes replaced by the terms 'inner life' or 'person-internal reality'.

The openings in the circumference lines of fig. 1 indicate that all the parts of ego-consciousness can relate to the person-external reality. In the middle of fig. 1 is a small circle. Later on, it will be made clear that this small circle represents the hole which may lead the receiver of conveyed person-internal meanings to the unfathomable depth and the impervious darkness of the produser's inner life. More details about the intricacies of ego-consciousness cannot be considered here (see Ey 1963; Scharfetter 1986, and references therein).

At the bottom of the sector in fig. 1 which encompasses cognitive life, the individual's ability to make inferences is located. It is signified by the hatched segment. Inferences are basic and indispensable to all sorts of interpretation. If fig. 1 functions as a turning wheel, then inferences will have an influence on all its movements. But this will not be discussed in this paper (Van de Velde 1984; 1986b; 1988c). 


\section{Fig. 1}

Let me now illustrate in which ways realized language phenomena may convey person-internal meanings and in which ways person-internal meanings are to be hypothesized outside language. These illustrations, however, can in no way provide an exhaustive picture of the richness and depth which person-internal meanings may have, as has been made plausible in more extensive papers (Van de Velde 1988a; 1988c).

As to the producer's cognitive life, (2) may impart something of the states of ego-consciousness which can approximately be represented by (2k)-(2n). For the sake of brevity, I do not mention all the possible interpretations of (2) which refer to the producer's states of self-reflection.

(2k) I reflect upon the fact that (2)

(21) I know that (2)

(2m) I realize that (2)

(2n) I think that (2)

In addition to the possible references which pertain to the producer's cognitive life, the utterance (2) may also convey person-internal meanings which concern the affective life of the producer. In that case, the potential for interpretative elaborations of (2) cannot be adequately coped with by the paraphrases (2o)-(2r).

(2o) I deeply regret that (2)

(2p) I do not like the fact that (2)

(2q) I am very unhappy about the fact that (2)

(2r) I can no longer bear the feeling that (2)

The utterance (2) may have resulted from the producer's striving for particular meanings of life, as they may be identified in soul-solidarity, reciprocity of emotions, mutual concern, tenderness, etc. In this regard, the itterance (2) may concern aspects of the producer's conative life. If 
so, it has to do with the producer's desires, longings, wishes, expectations, and the like, as becomes clear from (2s)-(2w).

(2s) My expectation to love her cannot be fulfilled

(2t) My desire to love her is useless

(2v) My longing to love her and to be loved by her is not satisfied

(2w) My wish to love her has no mutual meaning.

It is necessary to make the point here that (2k)-(2r) do mainly suggest which modal/attitudinal qualifications may be indicative of the individual's inner life. Such modal/attitudinal qualifications are predominantly concerned with what is not explicitly expressed by the verbal message. Moreover, the verbal message does not completely express person-internal meanings. Nevertheless, one cannot disregard the not explicitly and not completely expressed information: it is part of the whole gamut of semantic, referential, pragmatic and other variables which (co)determine the global interpretation of (2). In view of this inexplicitness and incompleteness, it would be an illusion to believe that one can fully account for the diversity, depth, and richness of the producer's person-internal meanings.

\subsection{On intruding into ego-consciousness}

When person-internal meanings are not completely and not precisely uncoverable, as appears from the foregoing subsection, what can be done? The inquisitive co-human who is really interested in the person-internal meanings of the producer can use language to inquire into the producer's inner life, to come psychologically closer to her/him and eventually to have a (partly successful) communicative contact about facets of her/his person-internal reality. For instance (s)he can ask a question such as (3) to which the producer can answer (2).

(3) How is your relationship with Amanda?

Let us assume here that the individual's ego-consciousness is comparable to an inner eye (Gregory, 1981). This inner eye can serve as a (makeshift) tool for introspection, self-analysis, and self-reflection. That is, when the interlocutor $\mathrm{R}$ asks the question (3) this may bring the producer of (2) not only to answer (2), but also thoroughly to inspect what (s)he meant by (2) and what has brought her/him to say (2). It may, however, also be the case that the producer of (2) has not sufficient insight 
into her/his ego-consciousness or that (s)he cannot appropriately express what is on her/his mind (Van de Velde 1988c).

For the purpose of illustration, I take two conic vessels (see fig. 2). The vessel on the left is open at the top and at the bottom. It stands for the inner life of the producer. Any time a person asks a question about the inner life constellations of the interviewee, (s)he may bring the interviewee to self-analysis, introspection, self-reflection, and the like. In so doing, (s)he is throwing a small ball into the interviewee's conic vessel.

When a question such as (3) is answered as in (2), then the interviewee $\mathrm{P}$ exposes the inner parts of the conic vessel to the interlocutor R. From that moment on, the small ball is illuminated. That is, in being told (2), the interlocutor $\mathrm{R}$ can follow the small illuminated ball which moves from point $A$ to point $B$ along the contours of the left conic vessel. The stronger the affective, cognitive and conative intimacy between the interlocutors, the better the ball may be illuminated. In looking very carefully, the receiver can notice that the illuminated ball makes elliptical movements.

This image signifies that the inquisitive interlocutor R can only approximate along elliptical detours to the centre of the inner life of $\mathrm{P}$. That is, R's inquisitive look may bring him/her further off and lead him/her closer to the centre of P's ego-consciousness. But (s)he can never reach the abso-

Fig. 2

lute core of P's inner life.

After the elliptical movements have ceased, the illuminated ball falls through the hole in B. This hole B is also signified by the small circle in the middle of fig. 1. From the point $B$ on, the person-internal meanings become un(re)coverable. With respect to point B, the French poet Gerard de Nerval has expressed himself in plain French words by starting the poem El Desdichado with "je suis le ténébreux ...". These words are per- 
fectly understandable in their public standard meanings. But their personinternal meanings remain cryptic to the alien psyche. From point B on, all attempts at identifying the deeper strata of the individual's inner life, particularly the search for the related person-internal meanings, amount to filling the vessels of the Danaids.

Let me refrain here from further digressions into the darkness and depth of human consciousness. All considerations which concern (2) and its possible interpretations in (2a)-(2w) confirm the view that person-internal meaning is a mystery or has much in common with mysteries (Van de Velde 1988a). Here, it should be clearly stated that it is an illusion to believe that a mystery can be understood. If one does not agree, then one can learn from the ancient oriental wisdom and from comparing the richness of Taoism with the depth of Buddhist and Christian thought that the more one intrudes into the mystery the greater grows the mystery. Any concern with theory construction about language and its meaning cannot but face the maze of meaning's mysteries.

\section{Can meaning be exactly identified in interpersonal communication?}

Does an interpersonal discourse exchange, in which the producer can become a receiver and vice versa by having successive turns, as is suggested by fig. 3 , increase the possibilities of uncovering person-internal meanings? Can a mutual questioning/answering/turn-taking and the reciprocal feedback to which this may give rise, enable interlocutors to decipher the cryptogram of person-internal meanings?

In order to show that the problems involved here are enormously complex I shall continue to consider dyadic communication as the prototype of the interpersonal exchange of information. In fig. 3, the dyadic communication is conceived of as an exchange of person-internal meanings. For this reason, the elliptical movements of the illuminated ball are now presented on both sides. That is, for all answers which the interlocutors provide about their inner life constellations, the illuminated ball can be followed in its elliptical movements.

The straight broken lines between the two sides of fig. 3 signal the channel of communication along which the reciprocal flow of information may take place. This channel of communication may concern hearing, seeing, smelling, tasting, and touching.

It should be emphasized here that language is a very restricted means of serving the purposes of multichannel information processing. Apart 
from the written medium with embossed characters such as Braille which serves the tactual stimulation of sightless people, language can only make use of two channels: the channels of hearing and seeing. This may produce a reverse effect in the senser299that receivers tend to overcompensate and accordingly add a lot of meaning to the verbal message (Van de Velde 1988c).

\section{Fig. 3}

But let us return to fig. 3 in which the interactive character of language is at issue. On both sides of fig. 3, the illuminated ball falls inevitably through the bottom of the two conic vessels. Due to this doubled Danaidic situation, the possibilities of meaning addition are enhanced more than ever. This can easily be illustrated by the following discourse exchange: a male person writes a female person a note which runs like (4). In so doing, he hopes that his strenuous reflecting upon his person-internal meanings of (2) may be met with clarity.

(4) May I not love you for old time's sake?

Needless to say, the female receiver cannot precisely uncover to what kinds of person-internal and person-external reality the phrase for old time's sake refers. Nor can she exactly reconstruct which person-internal meanings are carried along with the word love. In (4) and in other examples, the word love may refer to the idealizations of an individual's illusions. Apart from that, love has as many person-internal meanings as there are individuals who reflect upon it. As a consequence, the receiver of (4) may be led to limitless interpretative elaborations.

Suppose that, after all her interpretative elaborations of (4), she sends the shortest possible note to him with only the word yes in it. It is an illusion to maintain that the semantic, pragmatic and referential domain of this yes can in any accurate way be identified. This answer is a mystery. Logically speaking, yes means that the producer of (4) may not love her 
for old time's sake. As to the psychological facets of interpersonal communication, her yes may refer to her acceptance, approval, agreement, contentment, relief, happiness, etc. But her yes can also convey her unwillingness to hurt him or to make him lose face, etc. If she had answered no to (4), then the interpretation of this answer would be problematic as well. (Here, I do not go into the further complexities of answering yes or no to a question which contains a negation.)

No matter whether the man receives yes or no as an answer or that he receives no answer at all, he can continue to write and to send letters to her in order to make it clear and plausible why he sent the message (4). But any answer which the lady returns may give rise to more problems, because her expressed person-internal meanings cannot be exactly reenacted or precisely lived anew by the male receiver.

A lady who is aware of the problems which might arise from her yes or no or from other answers might suffer so much from unsolvable dilemmas that she prefers not to respond to the man's note. This lack of response in turn may give rise to the man's interpretation that she (deliberately) wraps herself in mystery or that she thinks he is not worthy of her answer, or that she is impolite, inconsiderate, conceited, and so on.

From the above considerations it can be seen that no formal representation of the propositional content of (2) and (4) can account for the meaning effects which these utterances may produce. Most meaning effects do, in fact, change the properties of meaning which are characteristic of (2) and (4), because the human brain transforms, by necessity, the information it receives. In the light of this, the interpretation of (2) and (4) can be seen as a large set of transforms $\left\{\operatorname{Trf}_{1}, \ldots . ., \operatorname{Trf} f_{n}\right\}$.

If the interpretation of (2) is the sum of the logically and linguistically oriented paraphrases (2a)-(2j) combined with the modal/attitudinal qualifications assumed for the person-internal meanings of (2k)-(2r), with the meaning hypotheses $(2 s)-(2 w)$ which concern the producer's conative life, and with all the possible transforms $\left\{\operatorname{Trf}_{1}, \ldots \ldots . ., \operatorname{Trf}_{n}\right\}$, then it can hardly be denied that interpersonal communication of meanings becomes merged into mystery. This holds, mutatis mutandis, also true for the interpersonal communication of meanings which can be achieved by means of (4).

\section{Can meaning be accurately grasped in its relation to the person-external reality?}

Many students of language may object that the discussion of sections 
3-4 is impertinent to the study of meaning. They may claim that it is of primary importance to investigate the relations between language and person-external reality. In so doing, they may be exclusively concerned with verbal utterances and their correlates/denotata in the world outside language. In the light of these exclusive concerns, let me come now to the question of how language meaning may relate to the person-external reality.

This is a question which has a very long philosophical tradition. I cannot go into the quandaries which belong to this philosophical tradition. I shall restrict myself here to considering the extensionalist approach to language meaning. The main reason for doing so is that this approach is probably the most empiristic of all concerns with the relations between language meaning and person-external reality.

In the extensionalist approach, language is seen to refer directly to reality. The advocates of extensionalism consider meaning assignment as the assignment of truth values. In this view, the interpretation of a fragment of language which has a propositional content depends on its being true or false in its referring to the person-external reality (Martin 1987 and references therein).

In extensionalism, no room is left for the states of ego-consciousness which are inevitably involved in meaning conveyance and in meaning assignment. This is why extensionalism cannot account for the mental (istic) facets of meaning and is probably not interested in the diverse illusory facets of language interpretation.

One main critical remark is to be made here: extensionalists share the following shortcoming: they ignore the fact that man is part of reality and that there is reality within the ego-consciousness of the wakeful individual. Moreover, their extensionalist assignment of truth values is dependent upon the correspondence of the propositional content with its empirical correlates in the world outside language. As will be seen immediately, this criterion does not hold for observational/descriptive statements such as the stick is straight or the stick is bent. Nor does it apply to (5) and to the overwhelming number of similar examples in which an individual imparts information about her/his ways of seeing/interpreting/evaluating her/his person-internal reality.

(5) Morality is a delicate act of adjustment on the soul's part, not a rule or a prescription. (D.H. Lawrence, Fantasia of the unconscious, p. 54)

Any assignment of a truth value to (5) requires, on the one hand, the 
unlimited uncovering of what is precisely meant by (5) and of which states of ego-consciousness (5) denotes. On the other hand, the assignment of a truth value to (5) is ultimately constrained to a control which is contingent on the person-internal reality of the receiver. That is, assigning a truth value to (5), cannot be accomplished without taking into account inner life constellations.

Here, the problem arises as to what is the basis for the conclusion that a specific interpretation of specific inner life constellations is correct and as such can be criterional for truth assignment. This problem is not chimerical nor fictive: if truth assignment is concerned with the correct correspondence between what is said and what is the case, then the assessment of this correct correspondence is due to what there is in ego-consciousness. For instance, when an individual assigns truth values to the stick is straight and to the stick is bent this is based on her/his perception of what is outside/inside the water and/or on her/his pertinent prior knowledge about light refraction. Both this perception and this knowledge are related to her/his ego-consciousness or are inalienable parts of her/his ego-consciousness.

Let me now return to (2). Suppose that an interpersonal communication takes place in which the receiver, after having read (2) in a confidential letter, responds by sending the note (6).

(6) Richness is in what one does not possess.

To provoke the extensionalist, I may ask the following: to what does (6) refer in the person-external reality? Or is its interpretation determined by its referring to values which reside in the person-internal reality? If one does not have a precise answer to this question, how then can any truth value be assigned to the propositional content of (6) ? When a person who is educated in the philosophical tradition of the East maintains that (6) is true and when an economist of the West holds that (6) is false, what then can be said about the truth value of (6) except that it is a matter for their respective ego-consciousness?

Whether (6) is to be seen in the extensionalist approach as meaningless or as paradoxical or as contradictory or as true/false cannot be justifiably decided, because there is no precisely delineated counterpart in the person-external reality to which richness directly refers. Or to put it in different terms, richness is a rich designator, but not a 'rigid designator', because it does not designate the same object in any possible world (Kripke 1972, 269). By the way, an alternative intensionalist interpreta- 
tion of (6) is not less problematic: any de dictu reading which involves the construction of possible worlds goes beyond the control of whether what is said in (6) is true or false.

In recent psychologically oriented frameworks, one could say that the assignment of a truth value is contingent on mental models. If so, then one should not disregard the self-imposed limitation that the metaphor of mental models has a purely cognitive orientation. With respect to fig. 1 and the foregoing considerations, this purely cognitive orientation is not rich enough to fully account for the multiplicity, diversity, depth and richness of human emotions and for the wealth of other inner life constellations.

In the end, the assignment of meaning/truth leads us to ask which good reasons or arguments an individual may have to answer the questions (7) and (8):

(7) When one knows that the propositional content $p$ is true/false, how does one (come to) know that $\mathrm{p}$ is true/false?

(8) When one does not know that the propositional content $p$ is true/false how does one (come to) know that one does not know that $\mathrm{p}$ is true/false?

Multidisciplinary writings pertaining to truth assignment and egoconsciousness have insufficiently investigated in what ways (7) and (8) are related to individual and collective illusions. Nor have they been satisfactorily concerned with the hubris of those who act in rational ways but rely on irrational/uncontrollable assumptions (Elster 1984).

Philosophy (of science) and logic will usually relegate the cases of actual illusion to (cognitive) psychology. The frameworks and conceptions of (cognitive) psychology, however, have rarely met with respect or approval in the eyes of the logician/philosopher (of science). A recent example is Hintikka's rejection of Johnson-Laird's ideas about cognitive models of syllogistic reasoning (Hintikka 1987, 197-200; Johnson-Laird 1983).

If the questions (7)-(8) concern the person-internal meanings of verbally expressed propositions, how then can the truth conditions of these propositions be specified and satisfied? More specifically, how can any individual know that (9) is true?

(9) I am not afraid.

The propositional content of (9) may have been false when it was expressed for the first time, but have become true after many repetitions. (From the effects of psychotherapy, propaganda, and manipulation we can learn that repetition makes propositions come true.) How are the tru- 
th conditions of (9) to be specified and satisfied when (9) relates to the complex propositional content of connected verbal phenomena as in (10)?

(10) I am not afraid I may not love her.

It has often been claimed by logically minded linguists, philosophers and logicians that the propositional content/meanings of utterances can be determined on the basis of the compositionality principle. In the light of this claim, the propositional content/meanings of (10) would be dependent upon the meanings of its constituents. Here, the following problem arises: can the compositionality principle reliably apply to the simple and complex propositions of (10)? It is clear that (10) includes the constituent (2). The many meanings which may be assigned to (2) (see sections 3 and 4) make it an illusion that a justified interpretation of (10) can be composed. Moreover, a complete and precise interpretation of (10) requires diverse sorts of knowledge including knowledge of its producer's inner life constellations. But is there any controllable basis for any knowledge claim with respect to the inner life constellations which are conveyed by (10)? Since there are no X-rays or no other technical means to discern what (10) denotes and to control whether (10) does or does not correspond with its producer's inner life constellations, the extensionalist risk of being under an illusion when interpreting (10) is permanent. This lack of control and the risk of being under an illusion have also negative consequences when it comes to the point of validating/evaluating any nonextensionalist theory construction about language/meaning.

\section{On theory construction about language/meaning}

Let me now come to the major problem of the present paper: what have the preceding considerations to do with linguistic theory construction? The answer is obvious: they are fundamental to the scientific study of language/meaning. The scientific study of language/meaning requires theories of a different nature. Linguistics is the scientific study of language. As such, it may, amongst other things, construct theories to account for its subject domain. As has been indicated before, language does not exclusively function as a purely physical subject domain. It has communicative functions which are due to the fact that it both carries meanings with it and that meanings can be assigned to it. Accordingly, any theory which focuses on language must account for the intricacies of meaning. Because the intricacies of meaning have also to do with the interactive character of language in use, they cannot be separated from the language users and from their ego-consciousness. In the light of this, the scientific 
study of language/meaning is necessarily concerned with inner life constellations. Inner life constellations are the origin, the destination and the check-point of language/meaning in operation. When a theory of language/ meaning is proposed it has to take inner life constellations into consideration.

If it is the primary function of a theory 'to predict facts, to explain why facts are as they are, and to unify as wide a variety of facts as possible' (Jensen e.a. 1989, 180) how is such a theory then to cope with the inner life constellations and with the related facts of meaning and meaning assignment which have been considered in the course of this paper? Is such a theory possible in the present state of language research?

With regard to the foregoing considerations and in view of the deceptive data of sophistry, rhetorical tricks and other abuses of logic/language meaning which I could not take into account here (Van de Velde 1986, 1988c, 1989b ), my answer is a straightforward no. This straightforward no has to be the answer if such a theory should be sufficiently general, sufficiently precise, sufficiently controllable and sufficiently capable of unifying the wide variety of inner life facts which are involved in meaning conveyance and meaning assignment.

But the wide variety of inner life facts is still of a much more extensive and a more diverse nature than could be suggested in the preceding sections. Any explanation of them requires the construction of partial theories. Let me give in (i)-(x) some examples of such partial theories. They are needed to explain why some of the inner life facts which have been considered in this paper are as they are and why naturally occurring or elicited language can serve to convey the person-internal meanings which are related to these inner life facts:

(i) a theory of universal and monolingual grammatical properties;

(ii) a theory of the meanings which are characteristic of natural language phenomena;

(iii) a theory of those actions which are denoted by language or which are suggested by language or which co-occur with language;

(iv) a theory of reference which accounts for the relations of language with the person-external reality;

(v) a theory of the communicative functions of speech acts and of the communicative intentions which underlie them;

(vi) a theory of contexts which co-occur with language phenomena or which are invoked by the receivers;

(vii) a theory of man's cognitive life and of its interactions with affective and conative life;

(viii) a theory of man's affective life and of its interactions with cognitive and 
conative life;

(ix) a theory of man's conative life and of its interactions with cognitive and affective life;

(x) a theory of human thinking processes which are responsible for the communicative functioning of language

The list (i)-(x) can, of course, be extended in many ways depending on how extensive the scopes of interest are and how far the aims of (combined/integrated) theories go. But let us confine ourselves to the list (i)-(x). So far, no partial theory out of the list (i)-(x) has been brought to the point of having a sufficiently explanatory, predictive and unifying power.

This is not the only drawback (Van de Velde 1979). Another disadvantage is the lack of rigorous testing and of experimental control. I cannot go into this disadvantage (Van de Velde 1989a). Let me only recapitulate that with respect to (vii), (viii) and (ix) the present paper has shown that it would be an illusion to believe in objective tools of checking those hypotheses which specifically concern person-internal meanings.

As to 'unifying as wide a variety of facts as possible', there is still no integrative theory which in its unifying attempts can explain that there are no limits to the variability of meaning and to the polyinterpretability of verbal messages. And if such a theory should exist, which type of explanation would it propose? To be more specific, would such a theory provide causalistic, functionalistic or deductive-nomological explanations (Van de Velde 1972, 194)? If its explanations were causalistic, then it would have to take the producer's inner life constellations as the causes of her/his polyinterpretable verbal behaviour (Van de Velde 1988c). If its explanations were functionalistic, then it would have to consider the inner life facts of intended meaning effects and the inner life facts of the produced meaning effects as the functions of indeterminate verbal messages (Van de Velde 1988c). If its explanations were deductive-nomological, then such a theory would have to rely on laws from which particular meanings and meaning effects could validly be deduced. But if the meanings and meaning effects are immensely variable, as has been shown before, how should they be deducible and predictable from laws? One would expect the contrary result, viz. that laws allow scholars to predict meanings and meaning effects which are not (immensely) variable. To make such predictions, a fully developed deductive-nomological theory should be constructed. 
So far, no such fully developed deductive-nomological theory exists for the realms of meaning. This is not to deny that there are deductively operating rules which provide possibilities of prediction within the realms of lexical semantics (and autonomous microsyntax). But they concern solely local meaning relations, such as the various kinds of class inclusion, part-whole relations, and the like. As to the global meaning of (sequences of) utterances and other co(n)textually amnifested facts, predictions can only be proposed by those investigators who idealize away from the thorny paths of language in use. As such, these investigators may be subject to self-deception. They may, in several ways, have closed their eyes and their ego-consciousness to the complications arising from person-internal meanings and to the impossibility of exhaustively explaining and precisely predicting them.

\section{Conclusion}

In the foregoing, I have not discussed interpretation in terms of a specific idealized explanatory picture. Instead, I have raised the realistic problem that the same utterance/text can be interpreted differently. I have assumed that the differences in interpretation are mainly due to those who are involved in verbal interaction.

In the perspective of verbal interaction, it has become clear that language users are crucial to (the study of) language and its meaning (effects). In the same perspective, the list (i)-(x) turns out to be highly incomplete: the foregoing remarks about ego-consciousness are but minimal preconditions to propose an expansionistic explanatory picture which is to be found in mind science and in brain science.

In this integrative movement of interest, explanations of man's meaningful verbal activities require superordinate theories about his brain functioning (Popper/Eccles 1977; Eccles 1984; Gazzaniga 1988 and further references therein). Needless to say, such expansionistic endeavours would make partial theories of the list (i)-(x) real Lilliput enterprises. But these expansionistic endeavours can guarantee a high level of generality. They can also provide a unifying platform for partial theories.

It has turned out that language is not to be seen as a self-contained subject domain, but as a highly variable tool for self-reporting activities which become part of a reciprocal meaning assignment. As such, language has a very complicated nature in that it belongs to the person-external reality and to the person-internal reality. This very complicated nature has not yet been accounted for in a sufficiently general, sufficiently pre- 
cise, sufficiently controllable and sufficiently unifying theory. More specifically, theories have not thoroughly coped with the diverse illusions which may arise from verbal polysemy and meaning variability. In the light of this, it is a realistic and reasonable endeavour to complement the methodological views on what theories should do with a sound sense of scepticism about what theories can do.

\section{Literature}

Ayer, A.J. (1956): The problem of knowledge. London: Macmillan/New York: St Martin's press 1956.

Bergenholtz, Henning/Schaeder, Burkhard (eds.) (1979): Empirische Textwissenschaaft. Aufbau und Auswertung von Text-Corpora. (=Monographien Linguistik und Textwissenschaft 39). Königstein/Ts.: Scriptor 1979.

Bromberger, Sylvain. (1987): "Rational ignorance", in: Vaina 1987, 333-352.

Conte, Maria-Elisabeth/Petöfi, Janos Sandor/Sözer, Emel (eds.) (1988): Text and discourse connectedness. Amsterdam/Philadelphia: John Benjamins 1988.

Davidson, Donald/Harman, Gilbert (eds.) (1972): Semantics of natural language. Dordrecht/Boston: Reidel 1972.

Dijk, Teun, A. van, (ed.) (1985a): Discourse and communication. New approaches to the analysis of mass media, discourse and communication. (=Research in text theory 10). Berlin/New York: W. de Gruyter 1985.

Dijk, Teun,A. van, (ed.) (1985b): Handbook of discourse analysis. 4 vols. London/ Tokyo: Academic press 1985.

Eccles, John, C. (1984): The human mystery. The Gifford lectures, University of Edinburgh 1977-1978. London/Boston/Melbourne/Henley: Routledge \& Kegan Paul 1984.

Elster, Jon. (1984): Ulysses and the sirens. Studies in rationality and irrationality (revised edition). Cambridge/London/New York/Melbourne: Cambridge university press/Paris: Editions de la maison des sciences de l'homme 1984.

Ey, Henri. (1963): La conscience, Paris: Presses universitaires de France 1963.

Garnham, Alan (1988): Artificial Intelligence. An Introduction. London/New York: Routledge \& Kegan Paul 1988.

Gazzaniga, Michael, S. (1988): Mind matters. How mind and brain interact to create our conscious lives. Boston: Houghton Mifflin 1988.

Gregory, Richard, L. (1981): Mind in science. A history of explanations in psychology and physics. Harmondsworth: Penguin 1981.

Harré, Rom. (1985): "Persuasion and manipulation", in: Dijk 1985a, 126-142

Hawthorn, Jeremy. (ed.) (1987): Propaganda, persuasion and polemic. London: E. Arnold 1987.

Hintikka, Jaakko. (1987): Mental models, semantical games and varieties of intelligence, in: Vaina 1987, 197-215.

Jensen, Per Anker/Sørensen, Finn/Vikner, Carl. (1989): Data, corpora, and linguistic research, in: Hermes 2, 1989, 179-186. 
Johnson-Laird, Philip (1983): Mental models. Towards a cognitive science of language, inference and consciousness. Cambridge: Cambridge university press 1983.

Johnson-Laird, Philip. (1988): The computer and the mind. An introduction to cognitive science. London: Fontana 1988.

Kripke, Saul, A. (1972): "Naming and necessity", in: Davidson/Harman. 1972, 253-355.

Lawrence, D.H. (1971): Fantasia of the unconscious. Psychoanalysis and the unconscious. Harmondsworth: Penguin 1971.

Levinson, Stephen, C. (1983): Pragmatics, Cambridge/New York/New Rochelle/Melbourne/Sydney: Cambridge university press 1983.

Lindsay, Peter, H./Norman, Donald, A. (1977): Human information processing. An introduction to psychology. New York/San Francisco/London: Academic press 1977.

Louch, A.R. (1966): Explanation and human action. Berkeley, Los Angeles: University of California press 1966.

Lyons, John. (1986): Language, meaning and context. London: Fontana 1986.

Martin, Robert, M. (1987): The meaning of language. Cambridge (Massachusetts)/ London: MIT press 1987.

Moore, Terence/Carling, Christine (1982): Understanding language: towards a postChomskyan linguistics. London/Basingstroke: Macmillan 1982.

Moore, Terence/Carling, Christine. (1988): The limitations of language. London/Basingstroke: Macmillan 1988.

Naess, Arne. (1968): Scepticism. London/New York: Routledge \& Kegan Paul 1968.

Petöfi, Janos, S. (1983a): "Explikation und Evaluation in der Textproduktion" und Textinterpretation, in: Petöfi 1983b, 1-22.

Petöfi, Janos, S. (ed.), 1983b. Texte und Sachverhalte. Aspekte der Wort- und Textbedeutung. (=Papers in textlinguistics 42). Hamburg: Helmut Buske 1983.

Petöfi, Janos, S. (1985): "Procedural aspects of text interpretation", in: Sözer 1985, 176188.

Petöfi, Janos, S., (ed.) (1988): Text and discourse constitution. Empirical aspects, theoretical approaches. (= Research in text theory 4). Berlin/New York: W. de Gruyter 1988.

Popper, Karl, R/Eccles, John, C, (1977): The self and its brain. Berlin/Heidelberg/ London/New York: Springer 1977.

Scharfetter, Christian. (1986): Schizophrene Menschen. Bewusstseinsbereiche und Psychopathologie. Ich-Psychopathologie des schizophrenen Syndroms. Forschungsansätze und Deutungen. 2. neubearbeitete Auflage, München/Weinheim: Psychologie Verlags Union/Urban \& Schwarzenberg 1986.

Sözer, Emel, (ed.) (1985): Text connexity, text coherence. Aspects, methods, results. (=Papers in textlinguistics 49). Hamburg: Helmut Buske 1985.

Vaina, Lucia M., (ed.) (1987): Matters of intelligence. Conceptual structures in cognitive neuroscience. Dordrecht/Boston/Lancaster/Tokyo: Reidel 1987.

Velde, Roger G. van de (1972): Wetenschapsteorie en linguïstiek. Brussel: Labor 1972.

Velde, Roger G. van de (1974): Zur Theorie der linguistischen Forschung. München: Hueber 1974. 
Velde, Roger, G. van de (1975): Metodologische aspekten van de linguïstiek. Leuven: Acco 1975.

Velde, Roger, G. van de (1979): Probleme der linguistischen Theoriebildung einer empirischen Textwisssenschaft, in: Bergenholtz/Schader 1979, 10-27.

Velde, Roger, G. van de (1984): Prolegomena to inferential discourse processing. (=Pragmatics and Beyond V, 2). Amsterdam/Philadelphia: John Benjamins 1984.

Velde, Roger, G. van de (1986a): Meaningfulness and meaning assignment, in: Linguistica Antverpiensia XX, 1986, 111-150.

Velde, Roger, G. van de (1986b): On the foundations of interpretation. Leuven/Amersfoort: Acco 1986.

Velde, Roger, G. van de (1988a): Das Mysterium der Bedeutung, in: Linguistica Antverpiensia XXII, 1988, 289-347.

Velde, Roger, G. van de (1988b): Inferences as (de)compositional principles, in: Petöfi 1988, 283-314.

Velde, Roger, G. van de (1988c): On missing meaning Leuven/Amersfoort: Acco 1988.

Velde, Roger, G. van de (1988d): The role of inferences in text organization, in: Conte/Petfi/Sözer 1988, 537-556.

Velde, Roger, G. van de (1988e): On some basic questions of cotext meaning, in: Spieghel Historiael 29, 1988, 9-32.

Velde, Roger G. van de (1989a): Reference, meaning, naivety, and self-deception, in: Linguistica Antwerpiensia XXIII, 1989.

Velde, Roger G. van de (1989b): Text and thinking. Preliminaries to discourse processing as reasoning reception (forthcoming monograph), 1989.

Williams, J.M./Watts, F.N./Macleod, C./Mathews, A. (1988): Cognitive psychology and emotional disorders Chichester/New York/Brisbane/Toronto/Singapore: J. Wiley 1988. 